\title{
Cartografía de un recorrido espiritual: el símbolo de la alimentación en la obra de J.D. Salinger*
}

Fecha de recepción: 02 de octubre de 2014

Fecha de aprobación: 13 de abril de 2015

\section{Resumen}

Existe un sistema de símbolos en la obra de Salinger cuya identificación no se presenta claramente y de manera puntual para el crítico, pues debe ser considerado en todas sus manifestaciones a lo largo de la narrativa salingeriana. Este símbolo se construye a partir del papel que cumple la comida en las distintas obras del autor, distinguiendo claramente dos grupos de símbolos relacionados: 1 . La comida como símbolo positivo que brinda comunión espiritual, y 2. La comida como símbolo negativo que representa un espíritu colmado de los valores del mundo material, por lo que el vómito se presenta a menudo como símbolo de una actividad purgativa. En este trabajo se pretende realizar una cartografía del símbolo de la alimentación en la obra de J.D. Salinger a partir de sus manifestaciones simbólicas en la superficie textual, buscaremos interpretar sus diversas funciones significativas.

Palabras Clave: J.D. Salinger, literatura norteamericana, simbolismo religioso, bananafish, alimentación

\footnotetext{
* El presente trabajo, que se clasifica como artículo de investigación, forma parte (en tanto versión resumida) de nuestra Tesis de Licenciatura, una investigación más amplia en torno a la obra del autor, titulada Influencias y formas de la intertextualidad en la narrativa de J.D. Salinger, desarrollada en la Facultad de Filosofía y Letras de Universidad Nacional de Tucumán, Argentina.

Citar: Lencina, E. (julio-diciembre de 2015). Cartografía de un recorrido espiritual: el símbolo de la alimentación en la obra de J.D. Salinger. La palabra, (27), 109-123.
}

\section{Eva Lencina}

UNT-CONICET

evalencina@live.com.ar

Licenciada en Letras por la UNT y cursa el Doctorado en Letras de la Universidad Nacional de Córdoba. Actualmente, integra el Instituto Interdisciplinario de Literatura Argentina y Comparada (I.I.L.A.C) e investiga la obra del escritor angloargentino William Henry Hudson gracias a una beca de posgrado otorgada por el CONICET. 


\section{Cartography of a spiritual journey: the symbology of food in the work of J. D. Salinger}

\section{Abstract}

There is a symbolic system in Salinger's work whose identification is unclear and appears inaccurately to the critic, for it hasn't been considered in all its manifestations throughout Salinger's narrative. This system is built on the role played by food in the author's different works, making a distinction between two groups of symbols: 1 . Food as positive spiritual symbol that provides spiritual communion, and 2 . Food as negative symbol representing a spirit filled with the values of a material world, for which vomit is often presented as symbol of purgative activity. In this paper we will attempt to make a mapping (or cartography) of the feeding symbolism in the work of J.D. Salinger. From its symbolic manifestations on the textual surface, we will seek to interpret its various signifying functions.

Key words: J.D. Salinger - American literature - spiritual symbolism - bananafish - feeding

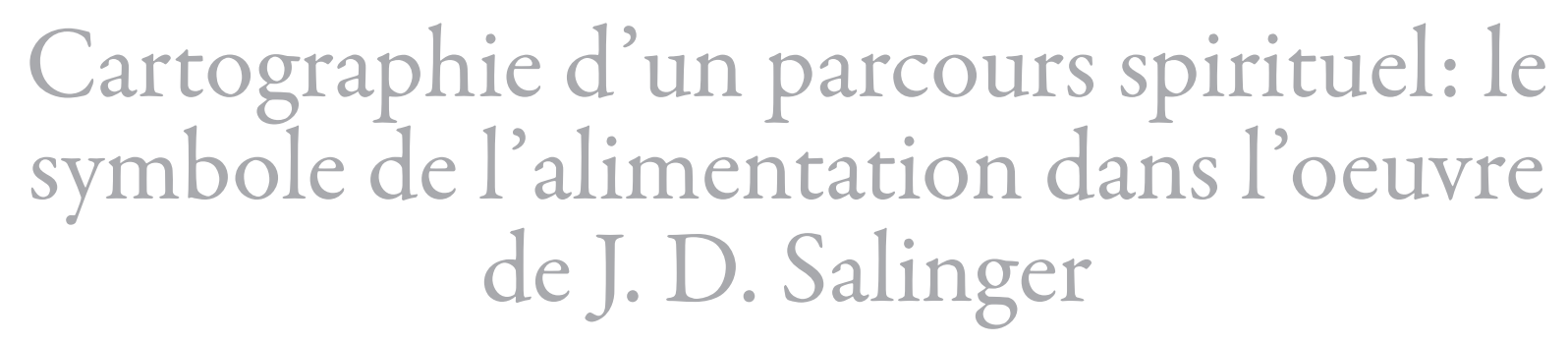

\section{Résumé}

Il existe un système de symboles dans l'œuvre de Salinger que le critique ne peut ni facilement ni précisément identifier. En effet, il convient d'étudier toutes ses manifestations dans l'ensemble de l'œuvre de l'auteur. Ce symbole se construit à partir du rôle joué par la nourriture chez Salinger. Nous pouvons distinguer deux groupes de symboles reliés entre eux : 1 . La nourriture comme symbole positif offrant une communion spirituelle et 2 . La nourriture comme que symbole négatif représentant un esprit habité par les valeurs du monde matériel. Dans ce contexte, le vomissement est fréquemment perçu comme symbole d'une activité purgative.

Dans ce travail, nous voulons faire une cartographie de la symbolique de l'alimentation dans l'œuvre de J.D. Salinger. A partir de ses manifestations symboliques dans le texte, nous tenterons d'interpréter ses diverses fonctions significatives.

Mots clés: J.D. Salinger; littérature nord-américaine; symbolisme religieux, bananafish, alimentation 


\section{Introducción}

Existen numerosos símbolos que pueblan la ficción del escritor norteamericano J.D. Salinger (1919-2010), respondiendo a la tradición del modernismo anglosajón que el autor heredaría a través de la lectura de T.S. Eliot y de los autores de la Lost Generation (Fitzgerald, Sherwood Anderson, Faulkner y Hemingway). Todos estos símbolos constituyen representaciones modernas de ideas que abrevan en el cristianismo y las religiones orientales que Salinger mismo practicaba.

Ejemplos de este tipo de símbolos espirituales son la gorra roja de Holden Caulfield en The Catcher in the Rye (1951), que expresaría la crística voluntad del joven de ser un "guardián en el centeno" o las cáscaras de naranja al comienzo del cuento “Teddy" (1953), que anticipan el desenlace final y sirven como metáfora de lo efímero que resulta la vida material dentro de la doctrina de reencarnaciones del hinduismo vedanta.

Sin embargo, existe un sistema de símbolos en la obra de Salinger cuya identificación no se presenta claramente y de manera puntual para el crítico, pues debe ser considerado en todas sus manifestaciones a lo largo de la narrativa salingeriana. Este sistema simbólico se construye a partir del papel que cumple la comida en las distintas obras del autor, distinguiendo claramente dos grupos de símbolos relacionados: 1. La comida como símbolo negativo que representa un espíritu colmado de los valores del mundo material, por lo que el vómito se presenta a menudo como símbolo de una actividad purgativa, derivado del anterior, y 2. La comida como símbolo positivo que brinda comunión espiritual.

En este trabajo pretendemos realizar una cartografía del símbolo de la alimentación en la obra de J.D. Salinger: a partir de sus manifestaciones simbólicas en la superficie textual, buscaremos interpretar sus diversas funciones significativas.

Recordemosque un símbolo es un signo cuya presencia evoca otra realidad sugerida o representada (simbolizada) por él, pero su relación con esta última depende de un sistema de representaciones culturales (la paloma como símbolo de la paz depende de un sistema de representaciones culturales $y$ bíblicas propio de occidente) o psicológica, dependientes del autor (el símbolo del agua en la poesía de Manrique tiene autonomía creativa y adopta así distintas aristas de significación a lo largo de la obra). Según Ducrot y Todorov, la relación entre el simbolizante y lo simbolizado es arbitraria, puesto que ambos términos existen independientemente del lugar que ocupen dentro del símbolo, y por lo tanto motivada, ya sea por parecido o por contigüidad.

"Tú no te das cuenta, pero tienes el cuerpo lleno de toxinas": J.D. Sallinger y su alimentación religiosa

Joyce Maynard, escritora que mantuviera una relación sentimental con J.D. Salinger a principios de la década del setenta, describe detalladamente el cuidado que el autor pusiera en su ascética alimentación. Esta consistía principalmente de frutas, verduras y carne de cordero ligeramente cocida y era considerada por el autor como parte integral de sus creencias religiosas orientales:

Jerry viene alimentándose de esta manera desde hace mucho tiempo y, dejando aparte la sordera parcial de un oído (reliquia de una herida de guerra), goza de excelente salud. La literatura de los Vedas nos dice que la duración natural media de un hombre es de ciento veinte años. Jerry se ha propuesto vivir ese período de tiempo (Maynard, 2000, p. 156).

Maynard narra también cómo Salinger utilizaba con frecuencia la práctica purgativa del vómito cuando consideraba 
que había ingerido alimentos demasiado tóxicos, instando también a su pareja a llevar esto a cabo (pp. 196-197).

Si bien estos datos pueden parecer irrelevantes o propios de una falacia biografista, resultan iluminadores del tema que nos ocupa, ya que demuestran que la alimentación tenía para el autor un sentido concreto $y$ estrechamente relacionado a su filosofía de vida, la cual se ha visto siempre reflejada en su producción literaria en forma de símbolos que abrevan en las tradiciones religiosas del budismo Zen, el hinduismo Vedanta y el cristianismo. De esta manera, el particular régimen alimenticio del autor viene a confirmar una vez más que, en el caso de Salinger, vida y obra se encuentran tan estrechamente relacionadas como los conceptos de cuerpo y alma, a los cuales se aplicarían los mismos principios de nutrición e intoxicación.

\section{La comida como símbo- lo negativo}

En estos casos, la comida representa una sobrevaloración del mundo material que ha intoxicado espiritualmente al sujeto, por lo que el vómito puede sobrevenir como purga. A continuación, expondremos es funcionamiento del símbolo de la alimentación en algunas obras de Salinger $^{1}$ :

\section{Los peces banana y el des-} tino de Seymour Glass

"A Perfect Day for Bananafish" (1948) es uno de los cuentos más conocidos de J.D. Salinger y aquél con el que el autor elige encabezar su colección de 1953 , Nine Stories. El relato es también uno de los que ofrecen mayor dificultad hermenéutica para el crítico, principalmente debido a su ambiguo final, en el que el protagonista comete suicidio sin razón aparente. Las razones que llevan a Seymour Glass, personaje capital en la obra de Salinger, a quitarse la vida giran en torno al símbolo que da nombre al relato: el pez plátano o pez banana, según la traducción, el cual protagoniza la confusa parábola que Seymour narra a la pequeña Sybil en la playa antes de volver al hotel en que se quitará la vida:

-Llevan una vida triste-dijo-. ¿Sabes lo que hacen, Sybil?

Ella negó con la cabeza.

-Bueno, te lo explicaré. Entran en un pozo que está lleno de plátanos. Cuando entran, parecen peces como todos los demás. Pero, una vez dentro, se portan como cerdos, ¿sabes? He oído hablar de peces plátano que han entrado nadando en pozos de plátanos y llegaron a comer setenta y ocho plátanos -empujó al flotador y a su pasajera treinta centímetros más hacia el horizonte-. Claro, después de eso engordan tanto que ya no pueden salir. No pasan por la puerta.

-No vayamos tan lejos-dijo Sybil-. ¿Y qué pasa después con ellos?

¿¿Qué pasa con quiénes?

-Con los peces plátano.

-Bueno, ¿te refieres a después de comer tantos plátanos que no pueden salir del pozo?

-Sí-dijo Sybil.

-Mira, lamento decírtelo, Sybil. Se mueren.

-¿Por qué?-preguntó Sybil.

-Contraen fiebre platanífera. Una enfermedad terrible (Salinger, 2008b, pp. 27-28).

Desde un principio se entiende claramente que los peces banana mueren después de atiborrarse de bananas y, gracias a otros indicios textuales dentro del relato, es posible relacionarlos directamente con una serie de personas superficiales que se encuentran intoxicadas espiritualmente por el mundo material del que no pueden ver más allá: Muriel Glass, esposa de Seymour, la señora Fedder, madre de Muriel, y la madre de Sy-

1 Por obvias cuestiones de espacio, esta versión reducida del trabajo no incluye el análisis de todas las obras de Salinger, sino una selección de los ejemplos más relevantes. 
bil, quien prácticamente abandona a su hija en la playa para ir a tomar martinis con una amiga. Luego de que la niña dice haber visto un pez banana llevando seis frutos en la boca, Seymour besa el pie de la pequeña y se despiden. Lo siguiente que hará será terminar serenamente con su vida.

Mediante su narración, Seymour persigue un propósito pedagógico (un tópico que atraviesa toda la obra de Salinger): el de enseñar a Sybil a ver los peces banana; esto es, a comprender una dimensión espiritual que suele estar vedada a la mayoría de las personas y a percibir, al menos simbólicamente, la frivolidad.

Las interpretaciones acerca de la muerte de Seymour Glass son variadas, pues algunos críticos se inclinan a considerar que Seymour sufriría de neurosis de guerra, basándose en los comentarios de Muriel y su madre en la primera sección del cuento. Otros críticos elaboran una interpretación basada en la construcción que Salinger hiciera de este personaje a partir de 1955, cuando Seymour Glass se erige en figura crística.

Sin embargo, nos atendremos aquí a una interpretación derivada exclusivamente de la parábola de los peces banana y del simbolismo de la alimentación. En este sentido, podemos diferenciar también dos líneas interpretativas: la que considera, apoyándose principalmente en la posterior caracterización del personaje en "Raise High the Roof Beam, Carpenters" (1955), que Seymour muere de felicidad y que la gula es más bien una golosía de los peces banana (Wiegand, 1987); y la que considera que la ingestión que cometen los peces banana, así como el propio Seymour, es negativa y corresponde al mundo material, por lo cual el personaje decidiría suicidarse, lo cual concuerda plenamente con la representación de la gula en la obra de Salinger y no entra necesariamente en contradicción con la felicidad que Seymour experimenta en "Carpenters", situada en 1942, debido a que entre su casamiento con Muriel y el momento en que se suicida, ha vivido la traumática experiencia bélica, algo de lo cual también debería purgarse.

Nos remitiremos, por lo tanto, a la segunda línea interpretativa y, en este sentido, la parábola (en tanto que de ella podría deducirse una enseñanza moral) de los peces banana constituye una narración metaficcional, pues representa el periplo existencial del propio Seymour, quien cometería el suicidio como una salida racional de la vida, en la que espiritualmente no logra avanzar debido a que la convivencia entre los hombres comunes, atiborrados de pensamientos banales (comida), lo ha intoxicado también. El suicidio es una purga espiritual y un escape hacia un lugar en que no hay peces banana ${ }^{2}$.

Por otro lado, la parábola de los peces banana constituye, en primer lugar, un símbolo continuado, debido a que a lo largo del texto aparecen términos simbolizantes (la charla entre Muriel y su madre, que alude principalmente a la incomprensión de Seymour y a temas vacuos como indumentaria femenina, y la charla entre la madre de Sybil y su amiga, que transita los mismos tópicos) que aluden e intensifican el concepto simbolizado (la frivolidad) y, en segundo lugar, una alegoría en tanto sistema simbólico diacrónico, debido a que la parábola sirve como significante de lo que le sucederá luego a Seymour, que configuraría la dimensión del significado. El sistema alegórico es diacrónico porque está constituido como una narración (con un desarrollo temporal): los peces banana son glotones, entran en pozos llenos de banana y, al atiborrarse, contraen la mortal fiebre platanífera.

2 Una mejor comprensión de "A Perfect Day for Bananafish" surge de poner este relato en relación con “Teddy" (1953), último de los nueve cuentos y en el que se esboza una explicación de lo sucedido con Seymour a partir de la teoría veda de la reencarnación (recordemos 
Seymour Glass, un artista del hambre

Existen, en ocasiones textos quepueden iluminar la lecturade otras obras sin necesariamente mantener con ellas una relación pautada por las categorías de la transtextualidad. Este bien podría ser el caso del parentesco textual que encontramos entre "Un artista del hambre" (1924), del gran escritor checo Franz Kafka (1883-1924) y el relato que nos ocupa. Si bien la presencia de Kafka en la obra de Salinger (quien leía en alemán y admiraba también al poeta Rainer Maria Rilke, como veremos más adelante) se explicita a través de un intertexto que el autor introduce en forma de una cita proveniente de los Diarios de Kafka al comienzo de "Seymour: an Introduction" (1959), no hay indicios textuales concretos que indiquen una relación similar con respecto a
"A Perfect Day for Bananafish", por lo que resulta preferible analizar lo kafkiano en Salinger como un "parentesco textual".

Los artistas del hambre fueron un fenómeno común en Europa durante los siglos XVIII y XIX, se dedicaban a ayunar por períodos prolongados y constituían una atracción en ferias y circos. Kafka centra su relato en retratar con sumo detalle la vida de un ayunador, por lo que el simbolismo de la alimentación que analizamos en la obra de Salinger encuentra en Kafka un válido punto de comparación.

Si consideramos a Seymour Glass como un "artista del hambre", podría decirse que la sociedad lo ha intoxicado, obligándolo a consumir alimento cuando él hubiera preferido mantener su ayuno. En este sentido, los relatos de Kafka y Salinger pueden ser interpretados como alegorías sobre la vida del santo o sobre la del artista, figuras que resultan hermanadas. El artista experimenta la visión y el sufrimiento de un santo ante la incomprensión de la sociedad. En este sentido, el ayuno del protagonista es una actividad tanto artística como espiritual.

Así como el artista del hambre finalmente pide perdón antes de morir, confesando que no debe ser admirado pues sólo ayunaba por no haber nunca encontrado comida que le gustara, lo mismo puede aplicarse al artista en general y a la figura del hombre sabio o bodhisattva (hombre que sigue el camino de la iluminación en la tradición del budismo Zen) en la obra de Salinger, quienes desde cierto punto de vista sólo perseguirían sus ideales porque los del hombre común no significan nada para ellos. Su condición excepcional los obliga a no poder se-

además que la colección se abre con un koan zen, clave de lectura que remite toda interpretación a la tradición budista). Teddy asegura haber sido en otra vida "un hombre que había alcanzado un gran progreso espiritual" (223), que posteriormente se encontró con una mujer y dejó de meditar, por lo cual habría perdido la gracia justo antes de llegar a la iluminación. Debido a que Seymour Glass y Teddy McArdle son dos figuras similares en la obra de Salinger, Teddy muy bien podría ser una clave de lectura para la vida de Seymour, quien habría retrocedido en su camino espiritual debido a su casamiento con Muriel, eligiendo luego terminar con su vida, de la misma manera que se sugiere que Teddy acepta su destino de morir al final del relato. Siguiendo esta hipótesis, resulta significativa la opinión de Teddy acerca de lo que "podría" sucederle más tarde en la pileta (caer y morir porque se encuentra vacía):

[...] Por ejemplo, tengo una clase de natación dentro de cinco minutos. Podría bajar a la piscina y encontrarme con que no tiene agua. [...] Podría pasar, por ejemplo, que yo me acercara hasta el borde, como para mirar al fondo, y que mi hermana viniera y mediera un empujón. Podría fracturarme el cráneo y morir instantáneamente [...]. Podría pasar, desde luego. Pero ¿qué tendría de trágico? ¿De qué podría tener miedo? Después de todo, yo no estaría haciendo más que lo que debo hacer, ¿̇verdad? (2008b:230, las cursivas son nuestras). En este sentido, tanto Teddy como Seymour no hacen más que obedecer el mandato de su destino, pero no con falta de libre albedrío o con tristeza, sino comprendiendo una dimensión de la vida que va más allá de lo trágico, al igual que el artista del hambre de Kafka se siente incapaz de luchar contra su destino (pues nunca ha encontrado alimento que le agrade), pero a la vez lo cumple con gozo, pues no desea más que ayunar. 
guir otro camino: la sabiduría de Seymour lo obliga a ver la falsedad del mundo moderno y a sentirse intoxicado espiritualmente por ella. Elige "no comer”, igual que el artista del hambre. Esto apunta a la ambigüedad que siente todo iluminado, quien ya no puede seguir otro camino que el del Bien y, por eso, siente que tampoco hay mérito en su virtud, pues no la siente una elección.

La confesión final del artista del hambre puede interpretarse tanto como proveniente de la humildad del ascetismo del artista, o bien como una última ironía kafkiana, en clave autobiográfica si nos remitimos a su propia experiencia de incomprensión por parte de la sociedad de su época, cuya máxima encarnación Kafka percibió en la propia figura paterna.

Puede señalarse una paradoja central en el relato de Kafka: para lograr el máximo nivel de ayuno, el artista del hambre está destinado a morir, por lo cual su final es tanto elección como destino. Del mismo modo, por haber tropezado con importantes distracciones en su camino espiritual, Seymour Glass ejercería, con su salida racional de la vida, una elección consciente de un destino que lo espera inexorablemente.

\section{Seymour Glass y las "Voces" de Rilke}

Hemos mencionado anteriormente la admiración que Salinger profesaba por el poeta checo Rainer Maria Rilke (1875-1926), el cual es aludido en "A Perfect Day for Bananafish" como "el único gran poeta de este siglo" (Salinger, 2008b, p. 15). Es posible identificar una relación intertextual entre el cuento que nos ocupa (y, por extensión, la colección Nine Stories en su totalidad) y una serie de nueve poemas titulada "Voces" que Rilke escribiera para su poemario, El libro de las imágenes (Das Buch der Bilder, 1902-1904).

Según Cotter (1989), existiría una voluntad por parte de Salinger de hacer que cada uno de sus Nueve cuentos correspondiera, al menos temáticamente, con las nueve "Voces" de Ri$\mathrm{lke}^{3}$. Siguiendo esta hipótesis, el relato "A Perfect Day for Bananafish" estaría inspirado en "La canción del suicida" (2009, pp.187-189) de Rilke, en la cual se escucha la voz de un hombre a punto de suicidarse, comparando su muerte con vomitar "esta cucharada de vida”. El suicidio del hombre es un escape hacia una dimensión en la que podrá "estar a dieta" del mundo, de la misma manera que el artista del hambre de Kafka desea que lo dejen en paz para proseguir con su ayuno y que Seymour elige una salida racional de la vida para eludir el destino al que están sujetos los peces banana.

En este sentido, el poema de Rilke constituiría no sólo un hipotexto concreto del texto salingeriano, sino también una clave de lectura que refuerza la interpretación del relato desde el punto de vista del simbolismo de la alimentación: la vida es claramente el alimento que el suicida rechaza, rogando incluso que le permitan vomitar ("dejadme vomitarme").

El Sargento X concilia el sueño en "For Esmé - with Love and Squalor" (1950)

El sistema simbólico que se delinea en la obra de Salinger encuentra su centro significativo en la comida, que representa estados espirituales positivos o negativos, y a menudo el vómito o las náuseas se presentan como culminación de un estado negativo del alma, que busca purgarse. Sin embargo, los elementos del sistema simbólico no se presentan todos juntos en cada obra. Éste es el caso de "For Esmé - With Love and Squalor" (1950), una de las obras más reconocidas de Salinger, principalmente por plantear el 
conflicto de los veteranos de la Segunda Guerra Mundial y la neurosis de guerra.

Recordemos la situación del Sargento X en la segunda sección del cuento, anunciada como "la parte sórdida o emotiva del relato" (155): luego del Día de la Victoria, se encuentra en Gaufurt, Baviera ocupando con sus camaradas una casa que perteneciera a una familia nazi. Se suceden luego una serie de acontecimientos que tienen por finalidad la mostración de su estado espiritual después de la experiencia bélica (mientras que la primera parte de la historia, que narra su encuentro con Esmé, sucede antes de la guerra). El protagonista, "un joven que no había salido de la guerra con todas sus facultades intactas" (156), sufre claros síntomas de estrés postraumático. Recién llegado del hospital, el Sargento X toma un libro de Goebbels que perteneciera a la hija de la familia y lee una anotación que reza "Santo Dios, la vida es un infierno"; con mucho esfuerzo y letra casi ilegible, responde con una cita de Dostoievski que afirma que el infierno es "el sufrimiento de no poder amar"; luego mantiene una conversación con su camarada, el cabo Clay, cuya superficial novia le recomienda epistolarmente a $\mathrm{X}$ que reciba ayuda psicológica por su colapso nervioso ${ }^{4}$. Mientras discute con Clay recordando cuando éste disparó a un gato durante un bombardeo, el Sargento X vomita repentinamente en el basurero.

La purga espiritual del Sargento $\mathrm{X}$ es previa a la lectura de la carta que Esmé le envió durante la guerra. Luego de leer sus palabras y de ver el reloj que la niña le envía, el Sargento $X$ "de pronto, casi en éxtasis, sintió sueño” (2008b, p. 169). El sueño repentino es un símbolo de iluminación o comunión espiritual que alivia al sujeto y se repite también como colofón en "Franny" y "Raise High the Roof Beam, Carpenters".

Entonces, el vómito ayuda al Sargento $\mathrm{X}$ a librarse de los horrores de la guerra, que de esta manera resultan comparables con una comida intoxicante.

\section{El desayuno budista de Holden Caulfield}

También en The Catcher in the Rye (1951) podemos encontrar algunas imágenes relacionadas con la comida que engrosan la lista de simbolismos. En el capítulo XXIV, Holden Caulfield abandona a toda prisa el departamento del señor Antolini, donde se había refugiado

3 Correspondencia Intertextual establecida por Cotter (1989):

Nine Stories de Salinger

Las Voces de Rilke

Frontispicio

Seymour Glass en "A Perfect Day for Bananafish"

La canción del suicida

Eloise en "Uncle Wiggily in Connecticut"

La canción del bebedor

Franklin Graff en "Just Before the War with the Eskimos"

La canción del idiota

El hombre que ríe y Omba en "The Laughing Man”

La canción del enano

Boo Boo Tenenbaum en "Down at the Dinghy"

La canción de la viuda

Esmé y Sargento X en "For Esmé - With Love and Squalor"

La canción de la huérfana

Arthur en "Pretty Mouth and Green My Eyes"

La canción del ciego

De Daumier-Smith en "De Daumier-Smith's Blue Period"

La canción del leproso

Teddy en "Teddy"

La canción del mendigo 
la noche anterior, después de despertarse siendo acariciado por su profesor. Nervioso, Holden se marcha y resuelve el ambiguo episodio para el lector diciendo: “iJo! Iba temblando como un condenado. Cosas así me han pasado ya como veinte veces desde muy pequeño. No lo aguanto" (2008a, p. 250). Luego de esto podemos suponer que el protagonista se encuentra especialmente afectado, pues lo sucedido se suma al episodio con la prostituta y el proxeneta que golpea a Holden en el hotel. En el capítulo siguiente, Holden intenta dormir un poco en la estación de trenes y luego, deprimido por lo acontecido y por la cercanía de la Navidad, busca algún lugar para desayunar y entra en una cafetería:

[...] en el momento en que me eché a reír me entraron unas ganas horribles de vomitar. De verdad. Hasta devolví un poco, pero luego se me pasó. No entiendo por qué fue. No había comido nada que hubiera podido sentarme mal y además tengo un estómago bastante fuerte. Pero, como les decía, se me pasó y decidí tomar algo. Entré en un bar con pinta de barato y pedí un café y un par de donas, pero no pude con ellas. Cuando uno está muy deprimido le resulta dificilísimo tragar. Pero por suerte el camarero era un tipo muy amable y se las volvió a llevar sin cobrármelas ni nada. Me tomé el café bebido y luego volví a la Quinta Avenida (2008a, p. 254).

Holden no es capaz de tragar la donas cuando se encuentra más atribulado espiritualmente. Incluso él mismo lo tematiza al decir "Cuando uno está muy deprimido le resulta dificilísimo tragar", pero esta explicitación no resta importancia al simbolismo de la alimentación. Si bien en este caso puede tratarse simplemente de una alusión, entra en correlación con las demás apariciones de este símbolo en la obra de Salinger.

Por otro lado, la importancia de esta escena en relación al simbolismo de la alimentación se ve reforzada al tener en cuenta el análisis de Dennis McCort acerca de la intertextualidad con la tradición Zen. Según este autor (McCort, 2001, p.126), la incapacidad de Holden para tragar las donas de su desayuno proviene de la tradicional colección china de koans compilada en el siglo XIII por el maestro Zen Wumen Hui-k'ai (1183-1260) y conocida popularmente por su nombre en japonés como Mumonkan (la traducción al inglés lleva por nombre The Gateless Gate). El texto en cuestión es el número 49, incluido sólo en algunas ediciones por no ser de la autoría Wumen Hui-k'ai sino de uno de sus discípulos, Amban (por lo que suele denominarse "La adición de Amban”). En él, Amban comenta que su maestro acaba de publicar un conjunto de 48 koans, en el que critica las palabras y acciones de los patriarcas (maestros de la tradición Zen), por lo cual Amban lo considera un "malicioso" y lo compara con un "un viejo vendedor de donas intentando coger a alguien que pasa por ahí para que trague sus donas. El cliente no puede ni tragar ni escupir las donas y esto le causa sufrimiento" (Senzaki y Reps, 1934 , 89; la traducción es nuestra). Para Amban, los koans compilados son como donas que nadie quiere tragar porque están de más en la tradición Zen (y aquí cita al mismo Buda, cuando dice "No hables. La verdad esencial consiste en ni siquiera pensar") pero que tampoco se puede evitar engullir, debido a que son maliciosamente presentados como parte de la tradición.

\section{Teddy McArdle y un quias- mo simbólico}

"Teddy" (1953) es otro de los relatos de J.D. Salinger que llama la atención debido a su abrupto e inesperado final. Al

4 La psicología tiene una representación negativa en toda la obra de Salinger, desde los médicos que examinan al iluminado Teddy hasta los psicólogos que recomienda la señora Fedder a Seymour. 
igual que Seymour Glass, el pequeño Teddy muere, habiendo anticipado este final durante su charla con Nicholson (de la misma manera que la parábola de los peces banana anticipa el final de Seymour). Teddy es un niño prodigio que despierta la curiosidad de científicos y académicos, pero su vida no se guía por el conocimiento y la inteligencia, sino por la tradición del hinduismo Vedanta, que plantea la existencia como un ciclo de reencarnaciones del cual el individuo sólo logra escapar mediante un gran ascenso espiritual.

Durante la charla que Teddy mantiene con Nicholson, un profesor universitario también interesado en el niño, surge nuevamente un símbolo relacionado con la alimentación cuando Teddy declara que la lógica occidental, representada bíblicamente por la manzana que Adán y Eva comen en el paraíso, es lo que le impide al hombre acceder a una dimensión espiritual superior.

$[\ldots]$ ¿Se acuerda de la manzana que Adán comió en el jardín del Edén, como se cuenta en la $\mathrm{Bi}$ blia? -preguntó-. ¿Sabe lo que había en esa manzana? Lógica. La lógica y demás cosas intelectuales. Eso es lo único que tenía dentro. Así que (esto es lo que quiero señalar) lo que tiene que hacer es vomitar todo eso si quiere ver las cosas como realmente son. Quiero decir que, si lo vomita, no va a tener más problemas con trozos de madera y cosas así. Ya no verá las cosas acabando todo el tiempo. Y sabrá qué es en realidad su brazo, si le interesa saberlo. ¿Comprende lo que quiero decir? ¿Cree que lo ha entendido? (2008b, p. 227, la cursiva es nuestra).

Y más adelante:

-¿Qué harías si pudieras modificar el sistema de enseñanza? -preguntó ambiguamente-. ¿Has pensado en eso alguna vez?

-[... No sé. Yo les haría vomitar hasta el último pedacito de manzana que sus padres y todo el mundo les han hecho morder (2008b, pp. 232-233).

La reaparición del símbolo de la alimentación en "Teddy" ilumina el significado último del mismo y constituye una de sus manifestaciones más completas, principalmente debido al entrecruzamiento de términos que el joven emplea. El símbolo de la alimentación se hace explícito al cruzar lo simbólico (el vómito de la manzana) con lo representado o significado (el conocimiento mundano o desespiritualizado de la lógica occidental), contenido que usualmente permanece bajo la superficie textual. Cuando Teddy dice que la manzana es la lógica que debe ser expulsada del cuerpo, se produce una suerte de quiasmo entre los términos del símbolo (simbolizante y simbolizado), explicitando su contenido. No en vano es este el relato que manifiesta más certeramente el pensamiento religioso de Salinger durante la primera etapa de su obra.

\section{El menú consagrado de Sickler's}

La nouvelle "Franny" (1955), con la que Salinger comienza una nueva etapa en su producción literaria luego de Nine Stories, constituye una fuente de análisis relevante para el tema que nos ocupa, puesto que el relato transcurre casi por completo en un restaurante y el comportamiento de los personajes con respecto a su comida resulta significativo.

En el relato, asistimos a la charla que Franny Glass (aunque sólo sabremos su apellido con la publicación de "Raise High the Roof Beam, Carpenters" a fines de 1955) mantiene con su novio Lane Coutell en un restaurante de moda el fin de semana del "partido contra Yale". Ambos son jóvenes universitarios en instituciones prestigiosas de la Costa Este, pero Franny parece estar atravesando un momento poco convencional para una chica de su clase. A través de la charla entre ambos, se percibe claramente que Franny sufre algún tipo de crisis espiritual e intenta refugiarse en la lectura de Relatos de un peregrino ruso, obra anónima ortodoxa del siglo XIX, que plantea una vida 
religiosa a través de la práctica de la Oración de Jesús, que el individuo debe llegar a internalizar hasta repetirla sólo con los latidas del corazón (por lo que también se denomina Oración del Corazón).

Por otro lado, Lane se muestra perceptiblemente impaciente ante las tribulaciones espirituales de su pareja y es descripto generalmente como un joven frívolo e intelectual, que avala el saber psiquiátrico antes que el religioso.

En este sentido, el simbolismo de la alimentación viene a reforzar esta polaridad entre los personajes: mientras que Lane ordena ansiosamente ancas de rana y caracoles, especialidad del lugar, Franny se muestra insegura y poco hambrienta. Finalmente ordena un sándwich de pollo y un vaso de leche, menú más propio de un niño que de una joven sofisticada. El crítico James Bryan nota también esta dicotomía en la elección del menú:

[Franny] En un restaurante deja significativamente intacto un sándwich de pollo, mientras que Lane lujuriosamente devora ancas de rana y caracoles (cosas sucias ${ }^{5}$ ). (Bryan, 1961, p. 228, la traducción es nuestra).

La comida avanzay, mientras come con ansia, Franny no logra probar bocado, sintiendo culpa y vergüenza cuando el mozo lo nota y termina llevándose su plato intacto. En este relato, la comida sólo se manifiesta como símbolo negativo en el caso de Lane, a quien le corresponde por su frivolidad. Franny se muestra enferma y se niega a comer: las razones de su ayuno bien pueden estar indicadas en “Zooey" (1957), relato en que continúa y se resuelve la historia de Franny.

Como veremos más adelante, durante su estancia en el departamento familiar Franny se niega también a probar el caldo de pollo que su madre, preocupada por su salud, le ofrece insistentemente. El ingrediente del caldo y del sándwich no deben ser ignorados, en especial cuando este detalle se ve reforzado en "Just Before the War with the Eskimos" (1949). Zooey declara que el pollo es un alimento consagrado, en especial cuando es ofrecido por un ser querido (según Bryan, representando la Eucaristía), y Franny no logra ingerirlo durante su crisis existencial justamente porque no se encuentra en paz consigo misma, sino intoxicada espiritualmente por la frivolidad que siente que la rodea.

\section{La comida como símbo- lo positivo}

Con este grupo de obras, el símbolo de la alimentación pasa a formar parte del sistema de dicotomías salingerianas (phony/ nice, etc.), coherente con la tendencia del autor a la polarización del mundo de la experiencia, debido a que el símbolo demuestra tener una reversibilidad binaria: es en ocasiones negativo y en ocasiones positivo. A continuación, analizaremos las obras de Salinger en que la comida aparece como un símbolo positivo de comunión espiritual o compasión.

\section{Un bocadillo de compasión de parte de Franklin Graff}

"Just Before the War with the Eskimos" (1948) es otro de los relatos de Nine Stories basado en el eclecticismo religioso que Salinger lleva a cabo a través de, en este caso, el budismo y el cristianismo. La historia nos presenta a una joven y egoísta Ginnie Maddox (quien insiste en cobrarle a su amiga Selena Graff el dinero que ésta le debe aunque sea Selena la que aporte siempre las pelotas para jugar al tennis, aunque su madre esté enferma y deba despertarla) y al ya no tan joven Franklin Graff, arruinado por los años de guerra e incomprensión (Lundquist, 1980, pp. 90-92, acierta en notar cómo el muchacho estaría, según el budismo Zen, encerrado en la rueda de la existencia, que implica sufrimiento hasta que

5 En el original "unclean things", refiriéndose a los alimentos impuros. 
el sujeto sea consciente del mismo y de la posibilidad de la iluminación).

El dispositivo narrativo que brinda reconciliación espiritual en la historia pertenece, una vez más, al orden de los alimentos. Mientras Franklin se encuentra absorto en sus propios sufrimientos (un corte en su dedo no para de sangrar, está de mal humor, le cuenta a Ginnie que tiene problemas cardíacos, etc.), Ginnie le dice que simplemente deje de tocarse el dedo. Esto representaría una suerte de iluminación para Franklin, quien sale de su abstracción y repentinamente ofrece a Ginnie los restos de un sándwich o bocadillo de pollo que el joven guardaba en su habitación. La chica se rehúsa pero termina por probarlo, conmovida por la insistencia de Franklin. Cuando Selena vuelve con el dinero, la actitud de Ginnie ha cambiado por completo: no acepta el dinero de su amiga, se muestra más amable y propone que hagan algo juntas.

Franklin Graff es una figura crística: aparece bajo la forma de los desposeídos o desgraciados, una falsa e incómoda apariencia que debe probar la virtud e incitar la compasión en el sujeto. Entonces, el bocadillo de pollo funciona como una suerte de sacramento. Al final del relato, Ginnie está a punto de tirarlo a la basura al salir de casa de los Graff pero recuerda un pollito de Pascuas que, hace unos años, tardó tres días en tirar luego de encontrarlo muerto al fondo de la papelera y Ginnie guarda el bocadillo en su bolsillo. Según Bryan, la referencia al pollito muerto durante tres días es una clara representación de Cristo:

Nuevamente mediante el uso de un eco banal, Salinger ha transfigurado una situación mundana en el Sagrado Sacramento. El sándwich de pollo es la Eucaristía. Esto se confirma cuando, saliendo del departamento, Ginnie pretende deshacerse del pedazo de sándwich que cortésmente había escondido en el bolsillo de su abrigo. Salinger entonces compara el sándwich de pollo con pollito de Pascuas que llevaba tres días muerto [en la cesta de basura de Ginnie] claramente representando el cuerpo de Cristo (Bryan, 1961, p.228, la traducción es nuestra).

La resolución del relato de Salinger nos indica un intertexto que refuerza también el simbolismo de la comida: el final mantiene claras similitudes con el final de "The Battler" (1925), de Ernest Hemingway, en el que Nick Adams se encuentra con una extraña pareja de marginados sociales en un bosque y se despide llevando una sándwich de jamón ${ }^{6}$. Al recordar que lo lleva, también lo guarda en el bolsillo. En el relato de Hemingway, se deja entrever que la pareja es homosexual. Si asumimos, junto con Lundquist, que el joven afeminado que pasa a buscar a Franklin es su pareja, estaríamos ante una reversión salingeriana de un cuento de Hemingway. Salinger utilizaría la estructura dada por Hemingway para adaptarla a su visión del mundo espiritualizada, resignificando el sándwich de jamón de Nick Adams en un sacramento bíblico que arranca al sujeto de la rueda de la vida.

Finalmente, vemos que Lundquist coincide también con la interpretación de Bryan del sándwich como un símbolo sacramental:

Este sándwich asume una cualidad sacramental y sugiere la fábula subyacente de la encarnación -la revelación del espíritu a través de la materia- que atraviesa esta historia y la mayorías de Nine Stories (1980, p. 91).

\section{Bessie Glass y su taza de} caldo de pollo consagrado

En “Zooey" (1957) asistimos a la resolución narrativa del conflicto presentado en "Franny": la menos de los Glass ha vuelto a casa después de descompensarse en Sickler's, trayendo con ella su crisis espiritual, la cual su madre no comprende, insistiendo en llamar a un médico, a un psiquiatra o a un cura. El lector conoce también a Zooey, actor de veinticinco años y hermano mayor de Franny. La obra está compuesta 
principalmente por los diálogos entre Zooey y su madre, Bessie y luego entre Zooey y Franny.

Hacia el final de la obra, luego de haber discutido largo y tendido acerca de la Oración de Jesús y de la frivolidad del mundo actual, Zooey le reprocha a su hermana el negarse a tomar la sopa de pollo que su madre, preocupada por su salud, le ha preparado para que se mejore:

-Te diré una cosa, Franny. Una cosa que sé seguro. $Y$ no te enfades. No es nada malo. Pero, si lo que quieres es la vida religiosa, deberías saber ya que te estás perdiendo todos los malditos actos religiosos que se celebran en esta casa. Ni siquiera tienes el sentido común de bebértela cuando alguien te ofrece una taza de caldo de pollo consagrado, que es el único tipo de caldo de pollo que Bessie le ofrece a alguien en este manicomio. Así que dime, sólo dime. Aunque te fueras a buscar un maestro por el mundo entero, un gurú, un santón, para que te explicara cómo rezar adecuadamente la Oración de Jesús, ¿de qué te serviría? ¿Cómo demonios vas a reconocer a un legítimo santón cuando lo veas, si ni siquiera reconoces una taza de caldo de pollo consagrado cuando lo tienes delante de tus narices? ¿Me lo quieres decir? (2003, pp. 203-204).

Zooey le cuenta a Franny cómo Seymour le enseñó a lustrarse siempre los zapatos antes de ir a la radio pensando en una señora gorda que puede estar escuchándolo. Franny también había recibido la misma enseñanza y, si bien Seymour nunca describió con demasiado detalle a la Señora Gorda, ambos hermanos la imaginaron enferma y sufriendo, esperando escuchar el programa de preguntas y respuestas en el que participaba. Zooey le dice a Franny que la Señora Gorda es Jesús (una vez más, el símbolo crístico toma la forma de los desposeídos) y, con esta revelación, Franny acepta tomar la sopa.

Una vez más aparece en la obra de Salinger la comida como un símbolo positivo. En este caso, se hace explícito que la sopa de pollo de Bessie Glass es un alimento "consagrado" debido al amor con el que la madre lo ha preparado. Bryan incluso sostienen que la lectura de "Zooey" puede iluminar el simbolismo cristiano de "Just Before the War with the Eskimos" (227) e identifica la sopa de pollo consagrada con una ofrenda que representa la Eucaristía.
El pollo como base de la sopa podría ser un ingrediente inocuo, pero vemos que se repite en "Just Before the War with the Eskimos" y en "Franny", en ambos casos siendo algo que las protagonistas se niegan a probar (aunque Ginnie finalmente acepte). Franny tardará un poco más en aceptar la comida consagrada, pero finalmente aceptará la sopa.

\section{Conclusión}

Hemos realizado una cartografía del funcionamiento de un símbolo cardinal y, como hemos visto, capaz de expresarse de forma reversible en la obra de J.D. Salinger. Por medio de un complejo sistema de reverberaciones mítico-religiosas, Salinger introduce en sus relatos el símbolo de la comida como un factor sintomático del estado espiritual de un individuo, un rasgo indicial de la capacidad de renuncia, o bien de la entrega desenfrenada a los apetitos sensuales del mundo material.

Si bien no hemos incluido la totalidad de los ejemplos que pueden citarse como representativos de este símbolo en la obra de Salinger, principalmente por cuestiones de espacio, consideramos que el balance realizado hasta el momento es lo suficien-

$6 \mathrm{Al}$ respecto podrá consultarse próximamente el artículo "Hemingway en la obra de Salinger: admiración literaria e influencia selectiva", que forma parte de nuestra Tesis de Licenciatura, titulada Influencias y formas de la intertextualidad en la narrativa de J.D. Salinger, actualmente en prensa. 
temente detallado como para arribar a algunas conclusiones provisorias.

En la tendencia dicotómica que domina la obra de J.D. Salinger, la comida es un símbolo reversible que puede presentarse con distintos grados de complejidad (llegando incluso a erigirse en la alegoría principal de "A Perfect Day for Bananafish") y que se presenta como un símbolo positivo sólo cuando constituye una ofrenda de amor o compasión de ecos bíblicos (esta ofrenda puede ser rechazada, pero es siempre positiva). Por otro lado, la comida se manifiesta como un símbolo positivo cuando se constituye en síntoma de un estado de intoxicación espiritual del sujeto, principalmente a causa de la frivolidad del mundo moderno, que se relaciona también con una sobreestimación del mundo académico y de la intelectualidad.

\section{Referencias}

Bloom, H. (ed.) (1987).J. D. Salinger (Modern Critical Views). New York - New Haven - Philadelphia: Chelsea House Publishers.

Bloom, H. (2000).J. D. Salinger's The Catcher in the Rye. Philadelphia: Chelsea House.

Bloom, H. (2008). J. D. Salinger (Modern Critical Views). New York - New Haven - Philadelphia: Chelsea House Publishers.

Ducrot, O., \& Todorov, T. (2003). Diccionario enciclopédico de las ciencias del lenguaje. Buenos Aires: Siglo XXI.

Cotter, J.F. (1989). A Source for Seymour's Suicide: Rilke's Voices and Salinger's Nine Stories. Papers on Language and Literature, 25(1), 83-98.

Kafka, F. (2009). Relatos completos I. Buenos Aires: Losada.

McCort, D. (2001). East Meets West: Zen and Rilke in Salinger's Catcher. En: Going Beyond the Pairs. The Coincidence of Opposites in German Romanticism, Zen, and Deconstruction (pp.117-132). New York: State University of New York Press.

Lundquist, J. (1980). J.D. Salinger. New York: Frederick Ungar Publishing Co.

Maynard, J. (2000). Mi verdad. Barcelona: Circe. 
Rilke, R. M. (2009). El libro de las imágenes. Madrid: Hiperión.

Salinger, J.D. (2003). Franny y Zooey. T. de Juan, trad. Barcelona: Edhasa.

Salinger, J.D. (2004). Levantad, carpinteros, la viga del tejado y Seymour: una introducción. C. Criado, trad. Buenos Aires: Edhasa.

Salinger, J.D. (2008a). El guardián entre el centeno. C.Criado, trad. Barcelona: Edhasa.

Salinger, J.D. (2008b). Nueve cuentos. E. Rius, trad. Barcelona: Edhasa.

Slawenski, K. (2010).J.D. Salinger. A life. New York: Random House.

Wiegand, W. (1987). J. D. Salinger: Seventy-Eight Bananas. En: Bloom, H. (ed.). J. D. Salinger (pp. 5-17). New York - New Haven - Philadelphia: Chelsea House Publishers.

Senzaki, N., \& Reps, P. (eds. y trads.). (1934). The Gateless Gate. Los Ángeles: John Murray. 